\title{
Treatment time to the end of thoracic radiotherapy has more predictive power for survival than radiation dose intensity in patients with limited-stage small-cell lung cancer receiving concurrent chemoradiation of more than $45 \mathrm{~Gy}$
}

\author{
JAE-UK JEONG ${ }^{1}$, WAN JEON ${ }^{2}$, SUNG-JA AHN ${ }^{1}$, YOUNG-CHUL KIM ${ }^{3}$, IN-JAE OH ${ }^{3}$, CHUL-KYU PARK ${ }^{3}$, \\ MEE SUN YOON ${ }^{1}$, JU-YOUNG SONG ${ }^{1}$, TAEK-KEUN NAM ${ }^{1}$ and WOONG-KI CHUNG ${ }^{1}$ \\ ${ }^{1}$ Department of Radiation Oncology, Chonnam National University Hwasun Hospital, Hwasun-gun, Jeollanam-do 58128; \\ ${ }^{2}$ Department of Radiation Oncology, Dongnam Institute of Radiological and Medical Sciences, \\ Gijang-gun, Busan 46033; ${ }^{3}$ Department of Internal Medicine, Chonnam National University \\ Hwasun Hospital, Hwasun-gun, Jeollanam-do 58128, Republic of Korea
}

Received May 16, 2019; Accepted October 7, 2019

DOI: $10.3892 / \mathrm{ol} .2019 .11107$

\begin{abstract}
The optimal protocol for thoracic radiotherapy (TRT) in combination with chemotherapy in patients with limited-stage small-cell lung cancer (LS-SCLC) remains elusive. The present study aimed to evaluate radiation parameters in association with survival outcomes. A total of 101 patients with LS-SCLC who completed TRT at $\geq 45$ Gy and concurrent chemotherapy were retrospectively reviewed. The median dose and duration of TRT were $50 \mathrm{~Gy}$ and 38 days, respectively. The median duration from the start of either therapy to the end of TRT (SER) was 60 days. The median survival for all patients was 26.9 months. The 3 -year local control (LC), progression-free survival (PFS) and overall survival (OS) rates were 52.0, 29.5 and $37.6 \%$, respectively, and the 5-year LC, PFS and OS rates were 50.1, 28.3 and $26.7 \%$, respectively. Univariate analysis revealed that patient age, tumor stage, timing and dose of TRT, SER, prophylactic cranial irradiation (PCI), and tumor response were significantly associated with treatment outcomes. Multivariate analysis revealed that stage was the only significant prognostic factor for LC $(\mathrm{P}=0.011)$, PFS $(\mathrm{P}<0.001)$ and $\mathrm{OS}(\mathrm{P}<0.001)$. Tumor response $(\mathrm{P}=0.014), \mathrm{PCI}(\mathrm{P}=0.007)$ and $\mathrm{SER}(\mathrm{P}=0.005)$ were significant predictors of OS. OS was improved in patients who achieved complete response, and their SER was $\leq 70$ days $(\mathrm{P}<0.001)$.
\end{abstract}

Correspondence to: Professor Sung-Ja Ahn, Department of Radiation Oncology, Chonnam National University Hwasun Hospital, 322 Seoyong-ro, Hwasun-eup, Hwasun-gun, Jeollanam-do 58128, Republic of Korea

E-mail: ahnsja@jnu.ac.kr

Key words: start date of any therapy to the end of thoracic radiotherapy, concurrent chemoradiotherapy, limited-stage smallcell lung cancer
Short treatment duration (SER $\leq 70$ days) was a significant predictor of OS in patients with LS-SCLC who completed planned TRT at $\geq 45$ Gy with concurrent chemoradiotherapy.

\section{Introduction}

Small-cell lung cancer (SCLC) usually presents as a bulky conglomerated mass with mediastinal invasion, with approximately two-thirds of patients presenting with metastatic disease at the time of initial diagnosis (1). Thus, rather than open thoracic surgery, chemotherapy is used as the first-line treatment, even in patients with apparently early-stage lesions. Despite the well-documented chemosensitivity of this tumor type, chemotherapy alone leads to high intrathoracic failure rates; however, a combination of thoracic radiotherapy (TRT) with chemotherapy offers benefits in controlling disease in patients with limited-stage SCLC (LS-SCLC) (2). Meta-analyses have reported early concurrent TRT as being beneficial in maximizing tumor regression compared with sequential chemoradiotherapy, resulting in favorable survival outcomes (3-5).

With respect to TRT protocols, the optimal intensity of radiation dose, including fraction size and total dose, is still not fully determined, despite well-designed clinical trials (6-10). Twice-daily TRT at a dose of 45 Gy and once-daily TRT at a high dose of up to $70 \mathrm{~Gy}$ in combination with chemotherapy show promising survival outcomes; however, radiation-related esophageal toxicity is remarkably high compared to that associated with a once-daily 45-50 Gy TRT regimen (6-9). Despite advances in radiation delivery enabling radiation dose escalation to $>60$ Gy in 2 Gy fractions (11), twice-daily TRT at 45 Gy is still considered the standard of care for patients with LS-SCLC (10).

The superiority of twice-daily TRT at 45 Gy may be explained by the shortened treatment duration and increased biologically effective dose (BED) of radiation, which are important predictors of survival $(12,13)$. Currently, panels of National Comprehensive Cancer Network recommend that TRT should 
be administered early, concurrent with the first or second cycle of chemotherapy. However, TRT could be delayed over the second cycle of chemotherapy due to huge tumor burden or poor performance. Thus, we aimed to evaluate the correlation of radiation parameters, such as dose intensity and treatment time, with survival outcomes in patients who had undergone concurrent chemoradiation therapy with curative intent.

\section{Materials and methods}

Patient inclusion. The medical records of 101 patients with LS-SCLC treated with definitive concurrent chemoradiotherapy (CCRT) between August 2005 and March 2014 were reviewed. Staging was determined using pretreatment computed tomography (CT), whole-body ${ }^{18} \mathrm{~F}$-fluorodeoxyglucose positron emission tomography $\left({ }^{18} \mathrm{FDG}-\mathrm{PET}\right)$, and brain magnetic resonance imaging (MRI). All patients were restaged according to the 7th American Joint Committee on Cancer staging system (14). Patients who received a TRT dose $<45$ Gy were not included in this analysis. This retrospective study was approved by the Institutional Review Board of Chonnam National University Hwasun Hospital (CNUHH-2018-181).

Treatments. All patients received either chemotherapy or TRT with chemotherapy on the first day of treatment. All patients received $4-6$ cycles of etoposide $\left(100 \mathrm{mg} / \mathrm{m}^{2}\right.$ per day on days 1-3) and cisplatin (60 mg/m $/ \mathrm{m}^{2}$ on day 1$)$, administered every 3 weeks. Hematologic toxicity and performance were monitored after each cycle of chemotherapy.

Patients received three-dimensional conformal radiotherapy using the Eclipse Treatment Planning System version 13.0 (Varian Medical Systems, Palo Alto, CA, US). Gross tumor volume (GTV) was defined as the total volume of the primary tumor apparent at the time of planning the first TRT and of the lymph nodes that were initially involved. Clinical target volume (CTV) was defined as GTV plus a minimum 7-mm margin and included the first-echelon draining lymph node station. No elective irradiation was performed on lymph node stations that were not involved. Timing of TRT was determined by the tumor board, and RT dose depended on the treatment protocol. When administering TRT at a $1.5 \mathrm{~Gy}$ dose twice-daily (BID), the total dose of $45 \mathrm{~Gy}$ was administered in 3 weeks. When the simultaneous integrated boost (SIB) technique was used, a CTV of 36-40 Gy in 1.8-2 Gy fractions and a GTV of 48-65 Gy in 2.2-2.4 Gy fractions were administered. For patients who were administered conventional fractions of 2 Gy, a CTV of 36 Gy and a GTV of 50 Gy were administered using the shrinking field technique. Upon administration of $50 \mathrm{~Gy}$, a follow-up chest CT was conducted and a booster dose of 60-65 Gy was administered to the apparently visible tumor. Prophylactic cranial irradiation (PCI) was performed for patients who consented to the treatment, completed all treatment regimens, exhibited no disease progression, and maintained good performance. The total dose and fraction schedule of PCI was $25 \mathrm{~Gy}$ in 10 fractions. Tumor response was re-evaluated using the response evaluation criteria in solid tumors after the completion of chemoradiation (15).

The BED for TRT was calculated according to following formula (16): $B E D=(n d)[1+d /(\alpha / \beta)]-(0.639 / \alpha)\left[\left(T-T_{k}\right) / T_{p o t}\right]$, where ' $n$ ' denotes the number of fractions, ' $d$ ' denotes the
Table I. Patient characteristics.

\begin{tabular}{|c|c|c|}
\hline Characteristics & Value & $\begin{array}{c}\% \text { of tota } \\
\text { patients }\end{array}$ \\
\hline \multicolumn{3}{|l|}{ Age, years } \\
\hline Median & 64 & \\
\hline Range & $43-80$ & \\
\hline \multicolumn{3}{|l|}{ Sex } \\
\hline Male & 88 & 87.1 \\
\hline Female & 13 & 12.9 \\
\hline \multicolumn{3}{|l|}{ ECOG performance status } \\
\hline 0 & 31 & 30.7 \\
\hline 1 & 68 & 67.3 \\
\hline 2 & 2 & 2.0 \\
\hline \multicolumn{3}{|l|}{ Smoking status } \\
\hline None or past smoking & 63 & 62.4 \\
\hline Current smoking & 38 & 37.6 \\
\hline \multicolumn{3}{|l|}{ T-stage } \\
\hline 1 & 7 & 6.9 \\
\hline 2 & 20 & 19.9 \\
\hline 3 & 37 & 36.6 \\
\hline 4 & 37 & 36.6 \\
\hline \multicolumn{3}{|l|}{$\mathrm{N}$-stage } \\
\hline 0 & 7 & 6.9 \\
\hline 1 & 17 & 16.8 \\
\hline 2 & 29 & 28.7 \\
\hline 3 & 48 & 47.6 \\
\hline \multicolumn{3}{|l|}{ Overall stage } \\
\hline IIA & 8 & 7.9 \\
\hline IIB & 8 & 7.9 \\
\hline IIIA & 30 & 29.7 \\
\hline IIIB & 55 & 54.5 \\
\hline \multicolumn{3}{|l|}{ Timing of TRT } \\
\hline$<3$ cycles of chemotherapy & 68 & 67.3 \\
\hline$\geq 3$ cycles of chemotherapy & 33 & 32.7 \\
\hline \multicolumn{3}{|l|}{ Fractionation of TRT } \\
\hline Conventional fractionation & 75 & 74.2 \\
\hline BID & 2 & 2.0 \\
\hline SIB & 24 & 23.8 \\
\hline
\end{tabular}

Dose of TRT

Median, Gy

Range

$45-65$

Dose of TRT, BED10

Median, Gy

Range

32.2-65.4

Duration of TRT

Median, days

Range

SER

Median duration, days

Range 
Table I. Continued.

\begin{tabular}{lcc}
\hline Characteristics & Value & $\begin{array}{c}\% \text { of total } \\
\text { patients }\end{array}$ \\
\hline $\begin{array}{l}\text { Total cycles of chemotherapy } \\
4\end{array}$ & 5 & 5.0 \\
5 & 12 & 11.9 \\
6 & 84 & 83.1 \\
Total treatment duration & 124 \\
Median duration, days & $66-170$ \\
Range & \\
PCI & 56 \\
Yes & 45 \\
No & \\
\hline $\begin{array}{l}\text { BED, biologically effective dose; BID, twice-daily; ECOG, the } \\
\text { Eastern Cooperative Oncology Group; PCI, prophylactic cranial irra- } \\
\text { diation; SER, duration from the start date of chemotherapy to the end } \\
\text { of thoracic radiotherapy; SIB, simultaneous integrated boost; TRT, } \\
\text { thoracic radiotherapy. }\end{array}$
\end{tabular}

fraction size, ' $\alpha / \beta$ ' is $10 \mathrm{~Gy}$, ' $\alpha$ ' is $0.3 \mathrm{~Gy}$, ' $\mathrm{T}$ ' denotes the overall duration of TRT with the first fraction administered on day 1, ' $\mathrm{T}_{\mathrm{k}}$ ' denotes the delay in tumor proliferation ('kick-off time' was assumed to be 21 days), and ' $T_{\text {pot }}$ ' the denotes potential doubling time of tumor clonogenic cells, which was set to 3 days for SCLC (17).

Follow-up and statistics. For the first 2 years after completion of treatment, patients were followed up every 3-4 months. After 2 years, patients were followed up at 6-month intervals. Local progression was defined as tumor recurrence within the radiation port areas. Tumor recurrence beyond the initial treatment site was defined as distant metastasis. We defined elective nodal failure as any regional nodal recurrence, including both supraclavicular lymph nodes outside the initial radiation port area.

Overall survival (OS) was defined as the duration between the first day of treatment and the day of patient death or the date of final follow-up. Progression-free survival (PFS) was defined as the duration between the first day of treatment and the day of detection of any discernible tumor on chest CT, whole-body ${ }^{18}$ FDG-PET, or MRI or the day of patient death. Adverse events were defined according to the National Cancer Institute Common Terminology Criteria for Adverse Events, version 4.0 (18). During the follow-up period, physicians observed the respiratory symptoms by physical examination and chest $\mathrm{CT}$ was also checked regularly.

Statistical analysis. Kaplan-Meier models were used for survival analysis of all potential factors affecting treatment. To assess the statistical significance of treatment parameters between groups, the Chi-square test was used. With respect to each prognostic and predictive parameter, the log-rank test was used to estimate LC, PFS, and OS rates. To avoid bias, we performed multivariate analysis with treatment factors
Table II. Cancer and treatment characteristics according to the tumor response.

\begin{tabular}{|c|c|c|c|}
\hline \multirow[b]{2}{*}{ Characteristics } & \multicolumn{2}{|c|}{ Tumor response } & \multirow[b]{2}{*}{ P-value } \\
\hline & $\begin{array}{c}\text { CR } \\
(n=62)\end{array}$ & $\begin{array}{c}\text { Non-CR } \\
(n=39)\end{array}$ & \\
\hline T-stage & & & 0.250 \\
\hline $1-3$ & 42 & 22 & \\
\hline 4 & 20 & 17 & \\
\hline N-stage & & & 0.849 \\
\hline $0-2$ & 33 & 20 & \\
\hline 3 & 29 & 19 & \\
\hline Overall stage & & & 0.257 \\
\hline IIA-IIIA & 31 & 15 & \\
\hline IIIB & 31 & 24 & \\
\hline Timing of TRT, cycles & & & 0.911 \\
\hline$<3$ & 42 & 26 & \\
\hline$\geq 3$ & 20 & 13 & \\
\hline Dose of TRT, Gy & & & $<0.001$ \\
\hline$\leq 50$ & 45 & 14 & \\
\hline$>50$ & 17 & 25 & \\
\hline Dose of TRT $\left(\mathrm{BED}_{10}\right), \mathrm{Gy}$ & & & 0.020 \\
\hline$\leq 50$ & 37 & 14 & \\
\hline$>50$ & 25 & 25 & \\
\hline Duration of TRT, days & & & 0.020 \\
\hline$\leq 40$ & 43 & 18 & \\
\hline$>40$ & 19 & 21 & \\
\hline SER, days & & & 0.576 \\
\hline$\leq 70$ & 40 & 23 & \\
\hline$>70$ & 22 & 16 & \\
\hline
\end{tabular}

BED, biologically effective dose; CR, complete response; SER, duration from the start date of chemotherapy to the end of thoracic radiotherapy; TRT, thoracic radiotherapy.

that were significant with respect to survival outcomes, with a P-value <0.05. The Cox regression model was used for multivariate analysis, and the Cox proportional-hazards model was used to calculate hazard ratios. Statistical analyses were performed using SPSS version 20.0 (IBM).

\section{Results}

Patient characteristics. Table I lists patient characteristics. The median age of the patients was 64 years. Among the 101 patients, $85(84.2 \%)$ were restaged as having stage IIIA or IIIB disease. The median dose of TRT administered to the patients was 50 (range, 45-65) Gy. The median duration of TRT was 38 (range, 23-60) days, and the median duration from the start date of any therapy to the end of TRT (SER) was 60 (range, 27-154) days. Overall, 68 patients (67.3\%) started TRT before the third cycle of chemotherapy; 62 patients $(61.4 \%)$ achieved complete response (CR) and 39 patients 
Table III. Treatment-related toxicity.

\begin{tabular}{lccc}
\hline Toxicity & Grade $3, \mathrm{n}(\%)$ & Grade 4, n $(\%)$ & Grade 5, n $(\%)$ \\
\hline Anaphylaxis $^{\mathrm{a}}$ & $1(0.9)$ & 0 & 0 \\
Dysphagia & $7(6.9)$ & 0 & 0 \\
Pneumonitis & $7(6.9)$ & 0 & $1(0.9)$ \\
Leukopenia & $34(33.6)$ & $13(12.8)$ & 0 \\
Febrile neutropenia & $9(8.9)$ & $1(0.9)$ & 0 \\
Anemia & $14(13.8)$ & 0 & 0 \\
Thrombocytopenia & $6(13.8)$ & $4(3.9)$ & 0
\end{tabular}

accurred in 1 patient due to chemotherapeutic agent, etoposide.

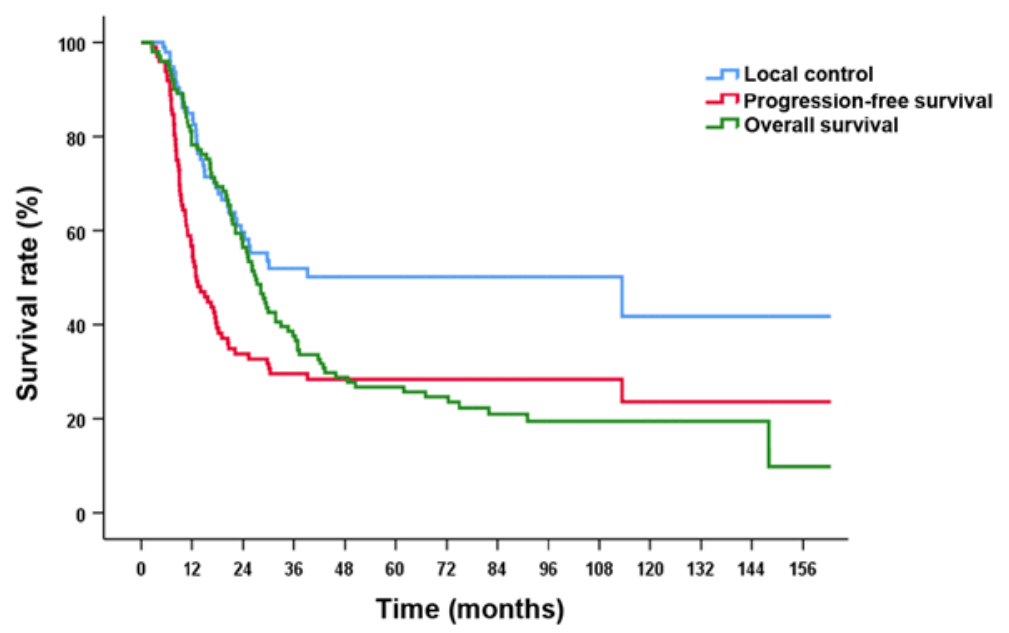

Figure 1. Local control, progression-free survival and overall survival rates of all patients.

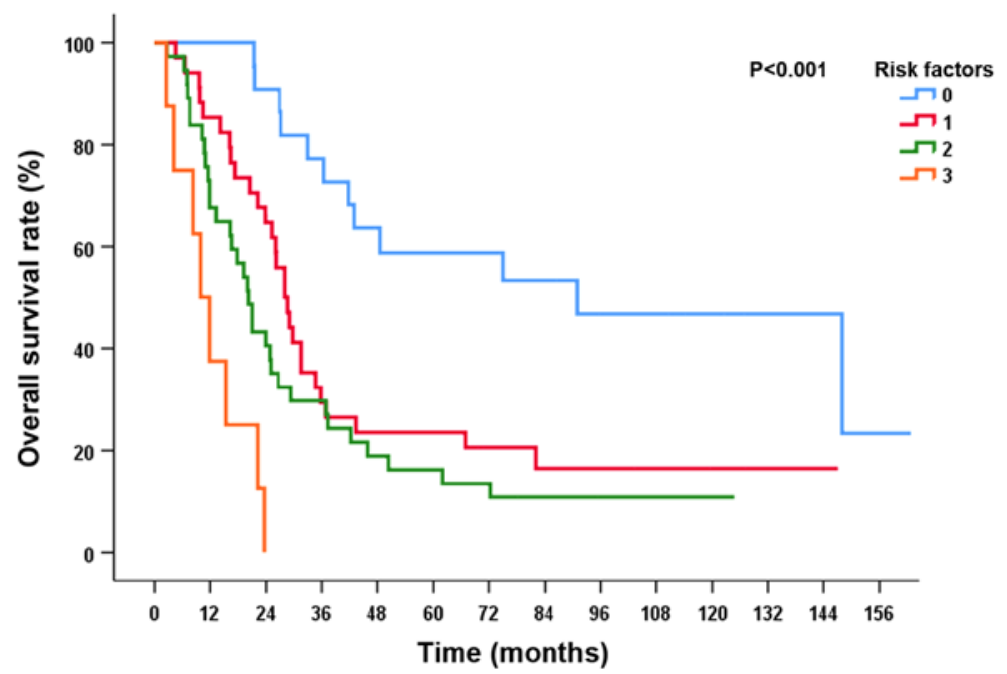

Figure 2. Overall survival rate according to the number of risk factors.

(38.6\%) exhibited partial response (PR) or stable disease after chemoradiation. PCI was performed in 56 patients (55.4\%).

The characteristics of each group of patients according to tumor response are shown in Table II. A lower dose or a BED lower than $50 \mathrm{~Gy}(\mathrm{P}<0.001, \mathrm{P}=0.020$, respectively $)$ and short duration of TRT ( $\leq 40$ days, $\mathrm{P}=0.020)$ were correlated with CR.

Treatment outcomes. Median follow-up period for all patients was 26.9 (range, 2.5-162.7) months and median survival was 
Table IV. Univariate analysis of clinical and treatment factors based on treatment outcomes.

\begin{tabular}{|c|c|c|c|c|c|c|c|}
\hline Variable & Patients, $\mathrm{n}$ & 3-year LC, \% & P-value & 3-year PFS, \% & P-value & 3-year OS, \% & P-value \\
\hline \multicolumn{8}{|l|}{ Age, years } \\
\hline$<65$ & 54 & 62.1 & \multirow[t]{2}{*}{0.212} & 35.9 & \multirow[t]{2}{*}{0.298} & 46.3 & \multirow[t]{2}{*}{0.002} \\
\hline$\geq 65$ & 47 & 37.2 & & 20.7 & & 27.7 & \\
\hline \multicolumn{8}{|l|}{ Sex } \\
\hline Male & 88 & 51.3 & \multirow[t]{2}{*}{0.615} & 27.6 & \multirow[t]{2}{*}{0.508} & 34.1 & \multirow[t]{2}{*}{0.068} \\
\hline Female & 13 & 58.9 & & 42.0 & & 61.5 & \\
\hline \multicolumn{8}{|l|}{ Smoking } \\
\hline None-past & 63 & 50.9 & \multirow[t]{2}{*}{0.980} & 29.8 & \multirow[t]{2}{*}{0.695} & 34.9 & \multirow[t]{2}{*}{0.996} \\
\hline Current & 38 & 54.3 & & 28.9 & & 42.1 & \\
\hline \multicolumn{8}{|c|}{ ECOG performance status } \\
\hline 0 & 31 & 51.4 & \multirow[t]{2}{*}{0.859} & 27.6 & \multirow[t]{2}{*}{0.436} & 29.0 & \multirow[t]{2}{*}{0.095} \\
\hline $1-2$ & 70 & 52.3 & & 30.5 & & 41.4 & \\
\hline \multicolumn{8}{|c|}{ Overall stage } \\
\hline IIA-IIIA & 46 & 63.0 & \multirow[t]{2}{*}{0.009} & 48.9 & \multirow[t]{2}{*}{$<0.001$} & 58.7 & \multirow[t]{2}{*}{$<0.001$} \\
\hline IIIB & 55 & 38.0 & & 11.0 & & 20.0 & \\
\hline \multicolumn{8}{|c|}{ Timing of TRT, cycles } \\
\hline$<3$ & 68 & 53.5 & \multirow[t]{2}{*}{0.471} & 32.7 & \multirow[t]{2}{*}{0.133} & 45.6 & \multirow[t]{2}{*}{0.017} \\
\hline$\geq 3$ & 33 & 49.3 & & 22.8 & & 21.2 & \\
\hline \multicolumn{8}{|c|}{ Dose of TRT, Gy } \\
\hline$\leq 50$ & 59 & 51.9 & \multirow[t]{2}{*}{0.411} & 31.1 & \multirow[t]{2}{*}{0.157} & 44.1 & 0.028 \\
\hline$>50$ & 42 & 53.7 & & 27.5 & & 28.6 & \\
\hline Dose of TRT & & & & & & & \\
\hline$\leq 50$ & 51 & 56.7 & 0.318 & 36.0 & 0.108 & 45.1 & 0.082 \\
\hline$>50$ & 50 & 46.9 & & 21.9 & & 30.0 & \\
\hline Duration of & & & & & & & \\
\hline$\leq 40$ & 61 & 47.2 & 0.723 & 28.9 & 0.367 & 41.0 & 0.249 \\
\hline$>40$ & 40 & 62.7 & & 31.1 & & 32.5 & \\
\hline SER, days & & & & & & & \\
\hline$\leq 70$ & 63 & 55.7 & 0.081 & 32.0 & 0.101 & 46.0 & 0.025 \\
\hline$>70$ & 38 & 45.8 & & 25.3 & & 23.7 & \\
\hline PCI & & & & & & & \\
\hline No & 56 & 37.9 & 0.095 & 19.1 & 0.017 & 23.2 & 0.003 \\
\hline Yes & 45 & 63.7 & & 41.0 & & 55.6 & \\
\hline Tumor respo & & & & & & & \\
\hline $\mathrm{CR}$ & 62 & 50.9 & 0.898 & 30.1 & 0.363 & 41.9 & 0.015 \\
\hline Non-CR & 39 & 54.0 & & 28.6 & & 30.8 & \\
\hline
\end{tabular}

BED, biologically effective dose; CR, complete response; LC, local control rate; ECOG, the Eastern Cooperative Oncology Group; OS, overall survival; PCI, prophylactic cranial irradiation; PFS, progression-free survival; SER, duration from the start date of chemotherapy to the end of thoracic radiotherapy; TRT, thoracic radiotherapy.

26.9 months. 3-year LC, PFS, and OS rates were 52.0, 29.5 and $37.6 \%$, respectively. 5-year LC, PFS, and OS rates were 50.1, 28.3 and $26.7 \%$, respectively (Fig. 1). Local failure occurred in 41 patients $(40.5 \%)$, and distant metastasis was detected in 54 patients $(53.4 \%)$. Elective nodal failure was observed in 12 patients $(11.8 \%)$. Sites of distant metastasis were located in the brain in $28(27.7 \%)$, bone in $11(10.8 \%)$, ipsilateral or contralateral lung in $5(4.9 \%)$, supraclavicular and cervical lymph nodes in 5, liver in 5, adrenal gland in 1, and diaphragm in 1 patients. Grade 3 radiation pneumonitis and esophagitis occurred in $7(6.9 \%)$ and $7(6.9 \%)$ patients, respectively. There were no cases of grade 4 or 5 radiation esophagitis. One patient died due to radiation pneumonitis after 6 months of TRT with a radiation dose of $60 \mathrm{~Gy}$ (Table III).

Predictive factors affecting treatment outcomes. In the univariate analysis, age $(\mathrm{P}=0.002)$, stage $(\mathrm{P}<0.001)$, timing of TRT $(\mathrm{P}=0.017)$, dose of TRT $(\mathrm{P}=0.028)$, SER $(\mathrm{P}=0.025)$, 
Table V. Multivariate analysis of clinical and treatment factors based on treatment outcomes.

\begin{tabular}{|c|c|c|c|c|c|c|}
\hline \multirow[b]{2}{*}{ Variable } & \multicolumn{2}{|l|}{$\mathrm{LC}$} & \multicolumn{2}{|l|}{ PFS } & \multicolumn{2}{|l|}{ OS } \\
\hline & $\mathrm{HR}(95 \% \mathrm{CI})$ & P-value & $\mathrm{HR}(95 \% \mathrm{CI})$ & P-value & $\mathrm{HR}(95 \% \mathrm{CI})$ & P-value \\
\hline Stage (IIA-IIIA vs. IIIB) & $2.29(1.21-4.36)$ & 0.011 & $3.61(2.15-6.07)$ & $<0.001$ & $2.49(1.56-3.98)$ & $<0.001$ \\
\hline Timing of TRT ( $<3$ cycles vs. $\geq 3$ cycles) & $0.74(0.28-1.95)$ & 0.550 & $1.11(0.49-2.50)$ & 0.798 & $1.68(0.80-3.54)$ & 0.168 \\
\hline Dose of TRT ( $\leq 50$ Gy vs. $>50$ Gy) & $1.30(0.62-2.72)$ & 0.482 & $1.56(0.90-2.68)$ & 0.108 & $1.57(0.95-2.59)$ & 0.076 \\
\hline SER ( $\leq 70$ days vs. $>70$ days $)$ & $2.18(0.89-5.30)$ & 0.084 & $1.46(0.67-3.15)$ & 0.331 & $1.93(1.22-3.07)$ & 0.005 \\
\hline PCI (Yes vs. No) & $1.55(0.79-3.05)$ & 0.200 & $1.59(0.95-2.65)$ & 0.072 & $1.87(1.19-3.02)$ & 0.007 \\
\hline Tumor response (CR vs. non-CR) & $0.87(0.42-1.80)$ & 0.720 & $1.11(0.65-1.89)$ & 0.693 & $1.76(1.12-2.77)$ & 0.014 \\
\hline
\end{tabular}

NS, not significant $(\mathrm{P}>0.05)$. BED, biological effective dose; $\mathrm{CI}$, confidence interval; LC, local control rate; CR, complete response; HR, hazard ratio; OS, overall survival; PCI, prophylactic cranial irradiation; PFS, progression-free survival; SER, duration from the start date of chemotherapy to the end of thoracic radiotherapy; TRT, thoracic radiotherapy.

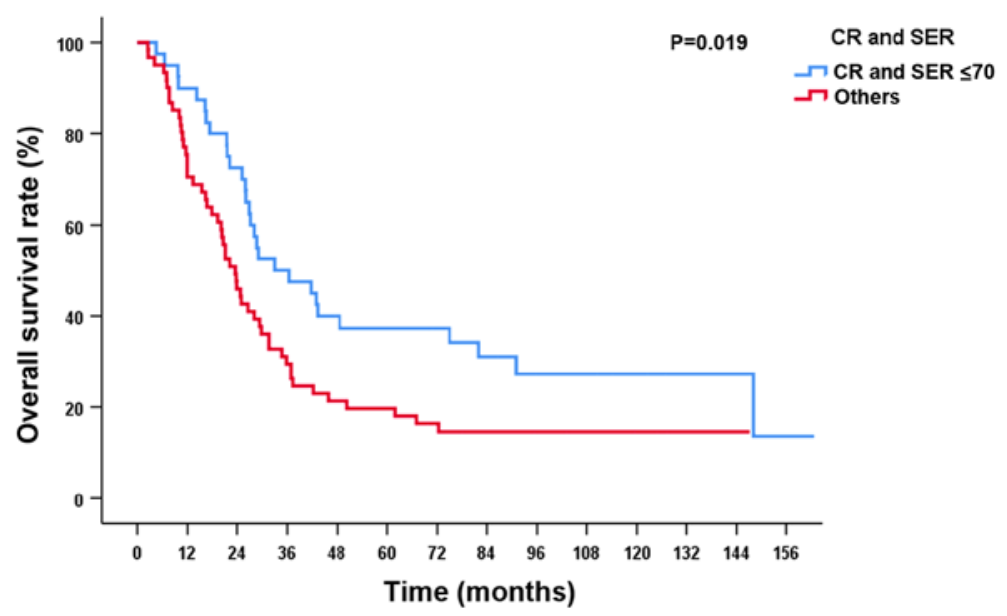

Figure 3. Overall survival rate according to tumor response and duration of therapy from the start of chemotherapy to the end of radiotherapy. CR, complete response; SER, duration of therapy from start of chemotherapy to the end of radiotherapy.

$\mathrm{PCI}(\mathrm{P}=0.003)$, and tumor response $(\mathrm{P}=0.015)$ were significant predictors of OS. Stage $(\mathrm{P}<0.001)$ and $\mathrm{PCI}(\mathrm{P}=0.017)$ significantly affected PFS. Stage $(\mathrm{P}=0.009)$ was the only prognostic factor related to LC (Table IV).

Multivariate analysis revealed that stage was the only significant factor affecting all treatment outcomes, including $\mathrm{LC}(\mathrm{P}=0.011)$, $\mathrm{PFS}(\mathrm{P}<0.001)$, and $\mathrm{OS}(\mathrm{P}<0.001)$. Other factors, such as SER $(\mathrm{P}=0.005)$, $\mathrm{PCI}(\mathrm{P}=0.007)$, and tumor response $(\mathrm{P}=0.014)$ were significantly associated with OS (Table V).

On the basis of multivariate analysis, patients were stratified into subgroups by risk factor, including stage IIIB, non-CR, and SER $>70$ days. There were significant differences in OS in accordance with the number of risk factors $(\mathrm{P}<0.001)$. Patients with $0,1,2$, and 3 risk factors presented with a 5 -year OS rate of 58.7, 23.5, 16.2 and $0 \%$, respectively (Fig. 2). The 5-year OS rate was $37.3 \%$ in patients who achieved CR with SER $\leq 70$ days and $19.7 \%$ in the other patients $(\mathrm{P}=0.019$; Fig. 3).

\section{Discussion}

Prolonged duration of treatment in cancer patients can affect survival outcomes, possibly because of accelerated tumor repopulation. SER significantly affects survival in patients with LS-SCLC (19). Our data also supported the clinical significance of treatment duration to the end of TRT on survival outcomes. De Ruysscher et al (19) reported that patients with SER $<30$ days exhibited improved survival. In the present study, we report a statistically significant difference at a cutoff of 70 days. The difference may be due to the heterogeneity of fractionation and timing of TRT in our patient population. This result reflects the importance of early combination of TRT with one or two rounds of chemotherapy (20). The probability of chemoresistance should be proportional to elapsed treatment time; drug-resistant SCLC is not completely cross-resistant to radiation (21). Thus, it is a reasonable strategy to start TRT as early as possible to prevent negative outcomes due to chemoresistance (22). However, in practice, because of the presence of bulky tumors, radiation oncologists hesitate to proceed with the combination of TRT and chemotherapy from the beginning, and usually, TRT is deferred until after chemotherapy, when the tumor regresses. Sun et al (23) reported that delaying TRT to the third cycle of chemotherapy does not result in inferior treatment outcomes compared with administering 
TRT with the first cycle of chemotherapy (median PFS of 11.2 months for late TRT vs. 12.4 months for early TRT, and median OS of 26.8 months vs. 24.1 months, respectively). In our study, median PFS and OS in patients with SER $\leq 70$ days were 16.5 and 29.4 months, respectively. If TRT was administered within the third cycle of chemotherapy, and if the patients exhibited no side effects necessitating interruption, treatment could be completed within 70 days. Therefore, it may be reasonable to assume that the important predictive factor in patients with LS-SCLC with respect to treatment duration is the completion time of TRT (SER), in addition to initiation of TRT at an early time point.

With respect to optimal dosing and fractionation schedules of TRT, several controversies remain. Turrisi et al (9) reported superior survival in LS-SCLC patients with a twice-daily accelerated regimen than in those administered a once-daily 45 Gy dose of TRT. Despite superior survival outcomes, twice-daily TRT has not gained widespread acceptance in routine clinical practice, predominantly because of the high prevalence of clinically significant esophagitis and the logistical problems involved. Thus, dose escalation studies with once-daily TRT in 2 Gy fractions are designed as experimental group. A pooled analysis of Cancer and Leukemia Group B studies using a single 2 Gy fraction per day revealed a median survival of 19.9 months, 2-year PFS rate of $26 \%$, and 5-year OS rate of $20 \%$ (8). It appears that TRT at 70 Gy once daily results in similar outcomes as TRT at 45 Gy BID. We obtained similar results, with 2-year OS and PFS rates of 56.4 and $33.8 \%$, respectively. A meta-analysis on the dose-response relationship in LS-SCLC patients showed that increased BEDs of TRT were correlated with prolonged survival and highlighted the potential clinical benefits of radiation dose escalation within the limited duration of TRT (13).

Patients with LS-SCLC who achieved CR after combined chemoradiotherapy demonstrated a higher median OS than patients who achieved PR (OS of 21.8 months vs. 14.9 months, respectively) (24). We also observed a median survival of 29.1 months in patients who achieved CR with concurrent TRT, compared with 20.5 months reported in patients with non-CR (data not shown). In a comparison of the underlying characteristics between patients with $\mathrm{CR}$ and non-CR in our study, we observed a significant difference in treatment duration and BED of TRT, because we did not escalate the dose of TRT in certain patients with a good response at administration of 50 Gy in 2 Gy fractions. Currently, we routinely prescribe a dose of TRT of at least $60 \mathrm{~Gy}$ in 2 Gy QD.

There were several limitations in our study. First, the timing of TRT was not consistent. Approximately $62 \%$ of the patients received early TRT; the administration of delayed TRT could affect patient survival and the evaluation of prognostic factors. Second, in our study, a higher dose of radiation was administered to patients with slow tumor regression. This resulted in poorer survival outcomes than in the lower-dose group and potentially led to a selection bias in the survival analysis.

In conclusion, patients with stage IIIB LS-SCLC who underwent CCRT demonstrated poorer survival outcomes than did those with stage IIA or IIIA LS-SCLC. SER was an important factor associated with the survival of patients who received 45 Gy TRT BID or 48 Gy TRT SIB, and more than
50 Gy CCRT QD. The best survival outcomes were expected in patients who exhibited CR with SER $\leq 70$ days.

\section{Acknowledgements}

Not applicable.

\section{Funding}

No funding was received.

\section{Availability of data and materials}

The datasets used and/or analyzed during the present study are available from the corresponding author on reasonable request.

\section{Authors' contributions}

JUJ and WJ contributed to acquisition of data, interpretation of data and drafting of the manuscript. SJA designed and conceived this study, and participated in the analysis and interpretation of data and drafting of the manuscript. JUJ, MSY and SJA mainly contributed to administration of radiotherapy. JYS mainly contributed to radiotherapy planning. YCK, IJO and CKP mainly contributed to administration of chemotherapy. TKN, JYS, WKC, MSY, YCK, IJO and CKP contributed to the interpretation of data and critical revision of the manuscript for important intellectual content. All authors read and approved the final manuscript.

\section{Ethics approval and consent to participate}

This retrospective study was approved by the Institutional Review Board of Chonnam National University Hwasun Hospital (approval no. CNUHH-2018-181).

\section{Patient consent for publication}

Not applicable.

\section{Competing interests}

The authors declare that they have no competing interests.

\section{References}

1. Rich AL, Tata LJ, Stanley RA, Free CM, Peake MD, Baldwin DR and Hubbard RB: Lung cancer in England: Information from the National Lung Cancer Audit (LUCADA). Lung Cancer 72: 16-22, 2011.

2. Pignon JP, Arriagada R, Ihde DC, Johnson DH, Perry MC, Souhami RL, Brodin O, Joss RA, Kies MS, Lebeau B, et al: A meta-analysis of thoracic radiotherapy for small-cell lung cancer. N Engl J Med 327: 1618-1624, 1992.

3. Takada M, Fukuoka M, Kawahara M, Sugiura T, Yokoyama A, Yokota S, Nishiwaki Y, Watanabe K, Noda K, Tamura T, et al: Phase III study of concurrent versus sequential thoracic radiotherapy in combination with cisplatin and etoposide for limited-stage small-cell lung cancer: Results of the Japan Clinical Oncology Group Study 9104. J Clin Oncol 20: 3054-3060, 2002.

4. Huncharek M and McGarry R: A meta-analysis of the timing of chest irradiation in the combined modality treatment of limited-stage small cell lung cancer. Oncologist 9: 665-672, 2004. 
5. Fried DB, Morris DE, Poole C, Rosenman JG, Halle JS, Detterbeck FC, Hensing TA and Socinski MA: Systematic review evaluating the timing of thoracic radiation therapy in combined modality therapy for limited-stage small-cell lung cancer. J Clin Oncol 22: 4837-4845, 2004.

6. Schild SE, Bonner JA, Shanahan TG, Brooks BJ, Marks RS, Geyer SM, Hillman SL, Farr GH Jr, Tazelaar HD, Krook JE, et al Long-term results of a phase III trial comparing once-daily radiotherapy with twice-daily radiotherapy in limited-stage small-cell lung cancer. Int J Radiat Oncol Biol Phys 59: 943-951, 2004.

7. Bogart JA, Herndon JE II, Lyss AP, Watson D, Miller AA, Lee ME, Turrisi AT, Green MR and Cancer and Leukemia Group B study 39808: 70 Gy thoracic radiotherapy is feasible concurrent with chemotherapy for limited-stage small-cell lung cancer: Analysis of Cancer and Leukemia Group B study 39808 Int J Radiat Oncol Biol Phys 59: 460-468, 2004.

8. Salama JK, Hodgson L, Pang H, Urbanic JJ, Blackstock AW, Schild SE, Crawford J, Bogart JA and Vokes EE: A pooled analysis of limited-stage small-cell lung cancer patients treated with induction chemotherapy followed by concurrent platinum-based chemotherapy and 70 Gy daily radiotherapy: CALGB 30904. J Thorac Oncol 8: 1043-1049, 2013.

9. Turrisi AT III, Kim K, Blum R, Sause WT, Livingston RB, Komaki R, Wagner H, Aisner S and Johnson DH: Twice-daily compared with once-daily thoracic radiotherapy in limited small-cell lung cancer treated concurrently with cisplatin and etoposide. N Engl J Med 340: 265-271, 1999.

10. Faivre-Finn C, Snee M, Ashcroft L, Appel W, Barlesi F, Bhatnagar A, Bezjak A, Cardenal F, Fournel P, Harden S, et al Concurrent once-daily versus twice-daily chemoradiotherapy in patients with limited-stage small-cell lung cancer (CONVERT): An open-label, phase 3, randomised, superiority trial. Lancet Oncol 18: 1116-1125, 2017.

11. Diwanji TP,MohindraP, Vyfhuis M,Snider JW III, KalavaguntaC, Mossahebi S, Yu J, Feigenberg S and Badiyan SN: Advances in radiotherapy techniques and delivery for non-small cell lung cancer: Benefits of intensity-modulated radiation therapy, proton therapy, and stereotactic body radiation therapy. Transl Lung Cancer Res 6: 131-147, 2017.

12. De Ruysscher D, Lueza B, Le Péchoux C, Johnson DH, O'Brien M, Murray N, Spiro S, Wang X, Takada M, Lebeau B, et al: Impact of thoracic radiotherapy timing in limited-stage small-cell lung cancer: Usefulness of the individual patient data meta-analysis. Ann Oncol 27: 1818-1828, 2016.

13. Zhu L, Zhang S, Xu X, Wang B, Wu K, Deng Q, Xia B and Ma S: Increased biological effective dose of radiation correlates with prolonged survival of patients with limited-stage small cell lung cancer: A systematic review. PLoS One 11: e0156494, 2016.

14. Edge SB and Compton CC: The American Joint Committee on Cancer: The 7th edition of the AJCC cancer staging manual and the future of TNM. Ann Surg Oncol 17: 1471-1474, 2010 .
15. Eisenhauer EA, Therasse P, Bogaerts J, Schwartz LH, Sargent D, Ford R, Dancey J, Arbuck S, Gwyther S, Mooney M, et al: New response evaluation criteria in solid tumours: Revised RECIST guideline (version 1.1). Eur J Cancer 45: 228-2247, 2009.

16. Xia B, Chen GY, Cai XW, Zhao JD, Yang HJ, Fan M, Zhao KL and $\mathrm{Fu}$ XL: The effect of bioequivalent radiation dose on survival of patients with limited-stage small-cell lung cancer. Radiat Oncol 6: 50, 2011.

17. Bepler G, Jaques G, Neumann K, Aumuller G, Gropp C and Havemann K: Establishment, growth properties, and morphological characteristics of permanent human small cell lung cancer cell lines. J Cancer Res Clin Oncol 113: 31-40, 1987.

18. Common Terminology Criteria for Adverse Events (CTCAE) Version 4.0. [Cited 2017 Oct 22] Available from: https://evs.nci.nih. gov/ftp1/CTCAE/CTCAE 4.03/Archive/CTCAE_4.0_2009-0529_QuickReference 8.5x11.pdf.

19. De Ruysscher D, Pijls-Johannesma M, Bentzen SM, Minken A, Wanders R, Lutgens L, Hochstenbag M, Boersma L, Wouters B, Lammering G, et al: Time between the first day of chemotherapy and the last day of chest radiation is the most important predictor of survival in limited-disease small-cell lung cancer. J Clin Oncol 24: 1057-1063, 2006.

20. Videtic GM: The role of radiation therapy in small cell lung cancer. Curr Oncol Rep 15: 405-410, 2013.

21. Willers H, Azzoli CG, Santivasi WL and Xia F: Basic mechanisms of therapeutic resistance to radiation and chemotherapy in lung cancer. Cancer J 19: 200-207, 2013.

22. Murray N, Coy P, Pater JL, Hodson I, Arnold A, Zee BC, Payne D, Kostashuk EC, Evans WK, Dixon P, et al: Importance of timing for thoracic irradiation in the combined modality treatment of limited-stage small-cell lung cancer. The National Cancer Institute of Canada Clinical Trials Group. J Clin Oncol 11: 336-344, 1993

23. Sun JM, Ahn YC, Choi EK, Ahn MJ, Ahn JS, Lee SH, Lee DH, Pyo H, Song SY, Jung SH, et al: Phase III trial of concurrent thoracic radiotherapy with either first- or third-cycle chemotherapy for limited-disease small-cell lung cancer. Ann Oncol 24: 2088-2092, 2013

24. Manapov F, Niyazi M, Gerum S, Roengvoraphoj O, Eze C and $\mathrm{Li}$ M: Evaluation of the role of remission status in a heterogeneous limited disease small-cell lung cancer patient cohort treated with definitive chemoradiotherapy. BMC Cancer 16: 216, 2016

This work is licensed under a Creative Commons Attribution-NonCommercial-NoDerivatives 4.0 International (CC BY-NC-ND 4.0) License. 